\title{
COM \\ "Going to these events truly opens your eyes". Perceptions of science and science careers following a family visit to a science festival
}

\section{Cherry Canovan}

\begin{abstract}
Young people's decisions to study post-compulsory science are strongly influenced by the attitude of their parents, but many families, especially those from deprived backgrounds, see science as 'narrow' and 'not for us'. We asked whether family attendance at a science festival - a growing but under-studied activity - could shift attitudes. Our mixed-methods study found parents from more deprived areas were disproportionately likely to say attendance had improved their perception of science. Parents from the most deprived areas were significantly more likely to feel increased positivity about their children pursuing science careers. Participants also reported learning about the breadth of careers in science. However we found no evidence that attendance boosted informal science activity in low-SES families.
\end{abstract}

Keywords

DOI

Informal learning; Public engagement with science and technology; Public understanding of science and technology

https://doi.org/10.22323/2.18020201

Submitted: 18th April 2018

Accepted: 16th November 2018

Published: 22nd January 2019

Introduction

Increasing levels of participation in post-16 STEM (science, technology, engineering and maths) education has long been a U.K. public policy objective, largely motivated by research identifying a so-called 'skills gap' in areas of the economy which rely on such expertise [see, for example, Confederation of British Industry, 2014]. However, progress has been slow. Attempts to build young people's interest through school-based interventions, such as trips to laboratories and ambassador visits, have not led to an increase in post-compulsory participation [Banerjee, 2017]; meanwhile representation of groups such as women and those from more deprived backgrounds remains stubbornly low, particularly in the physical sciences [Nunes et al., 2017; Henderson et al., 2017; Smith and White, 2011].

Specific measures to encourage young people to study science in schools and universities have been accompanied by broader efforts to engage the public with 
STEM. One manifestation of this has been a rapid growth in the number of science festivals. Since the first such festival, held in Edinburgh in $1989,{ }^{1}$ dozens of such events have been founded, with claimed positive impacts including increased public engagement in science. Academic research in this area has been sparse [Bultitude, 2014] and of variable quality [Jensen and Buckley, 2014]; however in recent years the literature has started to expand [e.g. Fogg-Rogers et al., 2015; Peterman and Young, 2015; Bevc, Young and Peterman, 2016; Kennedy, Jensen and Verbeke, 2017; Rose et al., 2017; Canovan and Luck, 2018].

Research into the factors that influence post- 16 science participation suggests that, while the school environment has a part to play, the influence of family and out-of-school experience is key [DeWitt, Archer and Mau, 2016]. We therefore posed the question: could family attendance at an informal event such as a science festival impact on parents' perceptions of science and science careers, and, by extension, have the potential to impact on children's future science participation?

\section{Theoretical framework}

\section{Science capital}

When considering the factors influencing STEM participation it is helpful to utilise the concept of science capital, which was developed by Archer, Dawson et al. [e.g. 2015] and draws on the large ASPIRES study into young people's science and career aspirations.

Science capital is a measure of an individual's science-related knowledge, as well as relevant experiences, family influence, attitudes and behaviours. Factors include scientific literacy, understanding of transferability of science skills, consumption of science media, and science-related social capital, for example knowing someone with a science job. Young people from families with high levels of science capital are more likely to wish to continue with post-compulsory science and to have science careers [Archer and Tomei, 2013].

Family science capital impacts young people's post-16 science aspirations in two ways. Firstly, some families increase the 'visibility' of science by enrolling children in clubs, taking them to museums or buying science magazines; and secondly they transmit an understanding of the value and transferability of science qualifications [Archer and Dewitt, 2017].

Low science capital is associated with low socioeconomic status (SES) [Archer, Dawson et al., 2015], and these societal links are influential in children's future science participation:

\footnotetext{
“...even at the age of 10/11, many working-class children are already disadvantaged and at risk of falling out of the 'leaky pipeline' that leads to a science career, even if they enjoy science." [Archer, DeWitt, Osborne et al., 2012]
}

HESA data shows that this is an effect which reaches beyond the problem of attracting young people from lower-SES backgrounds into higher education more

\footnotetext{
${ }^{1}$ https://www.sciencefestival.co.uk/about.
} 
generally. As Table 1 shows, maths, the hard sciences and medicine all attract fewer entrants from low-participation neighbourhoods than HE as a whole. ${ }^{2}$

Table 1. HESA widening participation data for young, U.K.-domiciled entrants for 2016/17. ${ }^{3}$

\begin{tabular}{|l|r|}
\hline Subject & $\begin{array}{r}\text { \% from low-participation } \\
\text { neighbourhoods }\end{array}$ \\
\hline All subjects & 11.4 \\
Physical sciences & 9.8 \\
Engineering and technology & 9.2 \\
Mathematical sciences & 8.6 \\
Medicine, dentistry and veterinary science & 5.8 \\
\hline
\end{tabular}

\section{What influences science participation?}

Researchers looked at responses to individual questions in a survey completed by schools participating in Enterprising Science, a project which built on the ASPIRES survey. These questions investigated how closely different facets of views and involvement in science were related to future participation and science identity [DeWitt, Archer and Mau, 2016]. Data from a nationally-representative sample was compared with that from pupils in groups that have historically been underrepresented in science, with some interesting findings emerging.

Across both survey groups the variable most closely related to future science participation was a proxy for scientific literacy, 'I know how to use scientific evidence to make an argument'. However a major difference between the two groups was seen in the next measure; among underrepresented groups, the next most influential variable was '(my parents) think science is very interesting' with a standardised beta of 0.152 , while among the national group this was eighth with $\beta=0.076$. In other words, parental attitudes to science are a much more important factor in post-compulsory science for low-participation groups than for the cohort as a whole.

Other influential variables among both groups included notions of 'usefulness' of science ('(Parents) Have explained to me that science is useful for my future' and 'A science qualification can help you get many different types of job') and out-of-school science-related activity such as talking about science to others and reading relevant books and magazines.

It is notable that of 11 variables highlighted by researchers, only two ('My teachers have specifically encouraged me to continue with science after GCSEs'; '(In school, how often) go to an after-school science club?') were related to a young person's school experience. This may be why some current research shows that school-organised informal science education, such as visits by STEM ambassadors or trips to laboratories, do not impact on post-16 science participation. Banerjee [2017], who studied data from more than 630,000 students, found:

\footnotetext{
${ }^{2}$ Biological sciences and computer sciences, by contrast, attract more entrants from low-participation neighbourhoods than $\mathrm{HE}$ as a whole.

${ }^{3}$ https: / / www.hesa.ac.uk/news/01-02-2018/widening-participation-tables.
} 
"Pupils who were registered by their schools for STEM enrichment and enhancement activities every year did not have any greater likelihood of continuing to study STEM subjects than their peers after compulsory education. This was true for all pupils, FSM [receiving free school meals] and black ethnic minority pupils."

By contrast, level of family interest in science has been shown to be a strong influence on future STEM participation. Data from Project Crossover, a study which surveyed more than 4,000 US doctoral students, shows that participants whose families were interested in science themselves developed an early interest in science [Dabney, Chakraverty and Tai, 2013], which is an important predictor of graduating with a science degree [Tai et al., 2006].

Given the key importance of the home environment in influencing science capital, it is therefore reasonable to ask whether informal education focusing on parents and shared family activity, rather than that delivered via the school environment, could have the potential to be more effective in boosting post-16 participation, particularly amongst more deprived groups.

\section{Informal science learning}

Informal science learning is a term used to describe a broad range of activities taking place outside of formal learning settings. A review of the U.K. sector conducted by the Wellcome Trust [Lloyd et al., 2012] defined the concept as:

“... activities that take place outside of the formal education system and seek to raise awareness of, interest in and engagement with science and other STEM subjects."

In their review of the Trust's findings, Matterson and Holman [2012] note the importance of such provision:

“...we are persuaded that informal science can engage and interest people in ways that formal settings cannot... experiences outside the classroom are essential to give meaning, relevance and context to the ideas that schools offer."

There is some evidence that participation in such informal activities is associated with long-term career interest in STEM. For example Dabney, Tai et al. [2012] used data from the PRiSE survey of nearly 7,000 US university students enrolled in introductory English courses to examine the effects of regular participation in science clubs and competitions prior to university entrance. They concluded that regular participants "had odds of selecting a STEM-related career in the university 1.5 times higher than those respondents not participating in such activities."

However informal science activities should not be viewed as an easy way to build science capital in young people. For example Dawson [2017], notes that some studies have shown that "Despite their involvement in... out-of-school science learning settings, youth participants still struggled to see themselves within science." 
Meanwhile Lin and Schunn [2016], who studied various types of informal science activity among American middle-schoolers, found that home-based activities such as science toys and consumption of science media were more strongly correlated with various dimensions of science capital than semiformal activities such as clubs, or than visits to museums. As home-based activities tend to be mediated by parents, this suggests that by influencing parents we may in turn influence their children.

\section{Barriers to science}

What barriers to science might young people experience that their parents may be able to influence? We have already discussed some - lack of parental interest in science, or understanding of its importance, and lack of out-of-school informal science activity, such as reading or talking about science. Other barriers that have been identified in the literature include perceptions of science as 'for the brainy' and as 'narrow'. Let us consider these in turn.

Science 'for the brainy'. A key perception held by young people about scientists is that they 'are brainy', a view held by around $80 \%$ of ASPIRES participants across years 6-9 and shared by their parents. As the authors note,

"The construction of scientists as 'brainy'... was underpinned by the discourse of science as a 'difficult' subject... Put simply, if science is a difficult subject, students have to be clever to do well in it." [Archer and Dewitt, 2017]

The authors found that while 'braininess' was not considered in a negative light per se, it led to an 'othering' of science which increased as young people progressed through education:

"... students clearly subscribe to the view that the further someone goes in the system, the more clever they have to be. Such a perception can certainly impact on aspirations, as individuals are likely to aspire to careers that they see as 'for me'. Science's reputation as a career 'for the exceptionally clever' is likely to act against many individuals seeing it as 'for me'." [Archer and Dewitt, 2017]

Perceptions of science as 'narrow'. Multiple studies have shown that school students lack awareness of the breadth of careers that science qualifications can lead to. Hill and Wheeler [1991] found that "students do not have a well-rounded appreciation of the nature of science and the work which scientists and technologists undertake". Cleaves [2005]'s findings add nuance:

\footnotetext{
"The majority of students who chose science... were distinguished by their deeper appreciation of what one might expect in a science career, despite evidence that such understanding had not been acquired in the science classroom."
}

In other words, students who pursue post-16 science are those with an advanced knowledge of the utility of science and of its transferability, that has been 
developed outside of the school environment. These young people's experiences are in contrast to those of other members of the student body, whose parents may share their lack of knowledge and thus be unable to advise their children where science progression is concerned. Archer, DeWitt and Dillon [2014] found that
“... most young people and their families have very little awareness of the diversity of careers that science can lead to and that the majority are not familiar with the transferable nature of science qualifications."

ASPIRES also found that working-class parents and children saw science as 'hard', even if they or their child were succeeding at the subject, and did not know what jobs science could lead to - a key piece of missing information [Archer and Dewitt, 2017].

Further evidence of the importance of this factor is given by the UPMAP study, which surveyed 7,000 students across the pre/post compulsory divide to find out why some continued to study maths and physics. UPMAP found that the strongest predictor of post compulsory physics study was the item "Physics will help me in the job I want to do in the future," [Reiss, 2013]. The effect size of this measure was more than three times as great as that of the next factor, "My teacher thinks I should continue with physics." Clearly if young people and their parents do not have a clear idea of the careers which physics, and by extension other sciences, can lead to, this is likely to have an adverse effect on post- 16 choices.

Research questions

Methods
Given the above findings, we decided to investigate a number of ways in which attendance at a family-oriented informal science intervention such as a science festival could potentially impact on parental attitudes and knowledge, and thereby on young people's science aspirations. Our objectives for investigation included:

i Can festival attendance increase parents' interest in science? This is a key predictor of future participation in science, particularly among families of lower SES;

ii Are festivals effective in disseminating information about the breadth and utility of science and the variety of science careers available, and in making such careers seem accessible? and

iii Does festival attendance boost informal science activity, such as science-related conversations, within families?

To examine this thesis, we initiated a mixed-methods study to be conducted among parents at the 2017 iteration of the Lancashire Science Festival. Mixed-methods studies are useful as they offer a number of different perspectives to the topic under examination. They also allow for comparison between results garnered using different techniques, thereby offsetting the shortcomings of any particular technique with supporting results gleaned by other methods. Our study incorporated questionnaires, interviews and a focus group to investigate the above research questions. Data collection for this project ran alongside an investigation into how visiting an informal event at a university campus impacted on parents' attitudes to higher education [Canovan and Luck, 2018]. 


\section{The Lancashire Science Festival}

The Lancashire Science Festival ${ }^{4}$ is a moderately-sized U.K. science festival held over three days at the University of Central Lancashire's campus in Preston, North West England. Preston is a medium-sized city which is one of the 50 most deprived local authority areas in England, although it has recently seen improvement across a number of measures. ${ }^{5}$ Seven of the city's 22 local authority wards are among the $10 \%$ most deprived in the country.

The festival consists of two days which are dedicated to school parties, followed by a third day aimed at family groups, particularly those with primary-age children. The research which forms the basis for this paper was carried out at and around the 2017 family day.

The event consists of four broad types of activity: shows - large-scale lecture demonstrations which are held in the university's lecture theatres; pre-bookable workshops; drop-in sessions; and two 'show floors', market-type areas consisting of numerous stands featuring practical activities that children can participate in.

Around 230 scientists and 30 organisations participate in the event, enabling visitors to meet and interact with a wide variety of people involved in science.

Our investigations at and after the festival were in four stages, as follows:

\section{Stage 1: pre-event questionnaire}

Attendees at the Lancashire Science Festival are asked to pre-register for the event in family groups. The individual registering the group completed a short questionnaire gathering data on SES (based on postcode by $\mathrm{IMD}^{6}$ ), level of education and attitudes to science. At this stage data was gathered from 1,724 registrants who attended the event. The average size of group was 3.7, meaning that our data covers $27 \%$ of attendees. The organisers estimate that more than half of attendees are under 18 , so this dataset represents a minimum of $54 \%$ of adults attending the festival.

\section{Stage 2: on-the-day interviews}

A team of trained research assistants (RAs) carried out face-to-face structured interviews on the day of the event. Interviews consisted of a number of Likert-scale questions, combined with a small number of open-ended questions designed to elicit a qualitative response. Previous studies at science festivals have been questioned for using prompted responses and therefore not gathering the interviewees' own words [Jensen and Buckley, 2014]; our study was designed to address this issue.

\footnotetext{
${ }^{4}$ For more information see https: / /lancashiresciencefestival.co.uk/.

${ }^{5}$ https://www.lancashire.gov.uk/lancashire-insight/deprivation/indices-of-deprivation-2015.

${ }^{6}$ Indices of Multiple Deprivation;

http:/ / www.gov.uk/government/statistics/english-indices-of-deprivation-2015.
} 
Research assistants were divided into groups of 2-4 and sent to different festival locations to interview adult attendees. The geographically diffuse nature of the event presented difficulties in the randomisation of interviewee selection; some RAs interviewed people who were queueing for events, in which case they were instructed to approach every fifth adult within the queue, but RAs assigned to the show floors simply approached parents while their children completed activities. Despite these methodological difficulties, the sample gathered was remarkably representative of overall attendees, both in terms of socioeconomic and educational status. Of 188 interviewees, $45 \%$ had postcodes in IMD deciles 1-5 (where the most deprived is 1 and least deprived is 10) and $66 \%$ had a degree; the corresponding figures for the total visitor cohort were $44 \%$ and $64 \%$.

In designing the interview structure, the desire of the researchers to gather detailed information had to be offset against the event organisers' wish to minimise disruption to the attendees, so the interviews were kept short. It should also be born in mind that the interviews were often conducted under less than ideal surroundings, for example with high noise levels or when interviewees were looking after their children. Training was given to the RAs in order to reduce errors and bias during the data gathering.

These on-the-spot interviews were designed to capture a snapshot of individuals' views 'in the moment'. Participants were asked both about their attitudes to science and about their attitudes to higher education more generally.

\section{Stage 3: post-event questionnaire}

An online questionnaire was sent to all attendees the day after the event. This consisted of a mixture of operational questions to enable the organisers to improve the event in future years, and research questions designed to elicit views on higher education and science.

The objective of this stage of data collection was to allow respondents to answer the questions after a period of consideration and at leisure, meaning that responses were able to be fuller and more considered. However the major drawback is that respondents at this stage were self-selected. Of 273 stage 3 responses, $36 \%$ were received from participants living in more deprived areas (IMD d1-5), compared to $44 \%$ in the body of attendees as a whole. Despite this caveat, the responses add depth to the information gathered using the on-the-day method and can be used in thematic analysis to tease out the effects being seen.

\section{Stage 4: focus group}

After completing analysis of the interviews and questionnaires, the researchers organised a focus group to further investigate the impacts of attending the science festival on respondents' views of higher education and of science careers.

Interviewees had been asked on the day whether they would be willing to be contacted by researchers; participants were drawn from the group who agreed. Our focus group consisted of five participants, four women and one man, from a diverse range of socioeconomic and educational backgrounds. 
Results and

analysis

\section{Festival attendees}

Registration data shows that festival visitors were disproportionately from less deprived areas, with $44 \%$ of families coming from IMD d1-5 (more deprived) postcodes and 56\% from IMD d6-10 areas. When we look at the local Preston area, two-thirds of households (67\%) live in wards that are ranked in IMD d1-5. Although ward-level rankings and postcode-level rankings are not directly comparable, these results suggest that visitors tended to be living in less-deprived areas than the local population as a whole.

In addition, a high proportion of attendees had attended university, with $64 \%$ of survey responses coming from graduates. By contrast, the 2011 census found that $27.2 \%$ of adults in England and Wales had a degree or equivalent. ${ }^{7}$

Attendees at the festival were significantly more scientifically literate than the general population. Scientific literacy was measured at registration by the question: 'How well informed do you feel about science?' Of attendees who answered this question $(n=1,666), 72 \%$ stated that they were fairly or very well informed about science. For comparison, a similar question asked in the governmentcommissioned 2014 Public Attitudes to Science Survey ${ }^{8}$ found that the corresponding national figure was $45 \%$ and that for the North West was $50 \%$.

An interesting point is that stage 2 interviewees showed a marked tendency to increase their estimation of their own science knowledge when questioned in person. Although, as noted, the interview group was representative of the general attendance, $84 \%$ of these respondents stated that they were well informed about science, a significant difference from the total attendee pool $(\mathrm{p}<0.001$ using a two-tailed chi-squared test). However when we examined the initial registration responses of these individuals, much of the difference disappeared, implying that responses were skewed by the presence of the interviewer. This effect was consistent across socioeconomic groups. We speculate that interviewees were either trying to 'please' the interviewer or were anxious to appear to 'fit in' - a possible example of interviewer bias [Katz, 1942] to be aware of. It would be interesting to pursue this finding in further studies.

It is important to note that findings from this study come with a broad caveat based on the identity of the people who attend science festivals. In general, attendees are more highly educated and more scientifically literate than the general population [Kennedy, Jensen and Verbeke, 2017; Manning, Lin and Goodman, 2013] and this was also the case at the LSF during our study. It therefore follows that any benefits of such events will only be fully felt when organisers attract a broader swathe of the population.

With this caution in place, let us consider participants' overall impressions of the festivals, and then examine our three theses in turn.

\footnotetext{
${ }^{7}$ http://www.ons.gov.uk/census/2011census.

${ }^{8}$ https:/ / www.gov.uk/government/publications/public-attitudes-to-science-2014.
} 


\section{Generic benefits of attendance}

Participants' reactions to attending the festival were strongly favourable, with words such as "interest" and "enjoyment" commonly employed in qualitative responses given at stages 2 and 3. This chimes with Manning, Lin and Goodman [2013]'s findings that science festival participants "reported becoming more interested in science, learning something new about science, experiencing science learning as more fun and enjoyable".

The most common benefit reported by participants across all social groups was that they were 'interested' in the science at the festival, cited by more than a fifth of respondents. Typical comments included:

\footnotetext{
"Interesting and motivating, [it] makes me more interested in science."

"I never fully understood what science actually covers. This opened my eyes and made science fascinating to me where before I seen it as boring and geeky."
}

A second key benefit was fun and enjoyment, cited by one-fifth. "It's fun, not nerdy," said one participant, while another added: "Makes science much more exciting, it's fascinating."

Another theme reported by participants was learning and gathering information. Typical comments ranged from the specific - "I learnt something about DNA and insulin" — to the general: "It's fantastic... I find it exhilaratingly informative."

The importance of learning via fun was emphasised by focus group participant Nicola: ${ }^{9}$

"I think it's a time to be fun... The learning was happening accidentally, anyway. That my children... are having a really good time with science is going to set them up for the future."

Finding an event fun and/or interesting is an important condition for gaining benefit from it [Kirkpatrick, 1996], but our study aimed to discover whether attending a science festival can have other impacts, as previously laid out. Let us explore the three facets of our thesis in turn.

\section{i. Parental perceptions of science}

As noted above, a significant proportion of stage $2 / 3$ participants reported that they or their children found the science festival interesting. However finding something 'interesting' does not necessarily imply a longer-term change of opinion about it. When we focus more tightly on the effect that visiting the festival had on parents' perceptions of science, some interesting findings emerge.

At stage 2 we asked the open question: "In a few words, what impact has your visit to the Lancashire Science Festival had on your perception of science?" Although

\footnotetext{
${ }^{9}$ Names of focus group participants have been changed.
} 
the question asked adult respondents explicitly to comment on their own experience, many spontaneously talked about their children in their answer. For example, one respondent said: "I found it interesting and educational," — a response relating to their own experience - while another said: "This is a good way to get kids involved in science," i.e. relating the question away from themselves and towards their children. Some responses contained both facets.

Results from this question were coded for whether a) the respondent reported a positive impact on their own perception of science and b) the respondent reported a positive impact on their children's perception of science. These results were then analysed on the basis of socioeconomic status, represented by IMD decile.

Overall, $28 \%$ of interviewees volunteered a positive impact for their children, with no significant differences between socioeconomic groups. Meanwhile $70 \%$ of total respondents reported a positive impact on themselves; however on this measure, significant differences were seen. Of respondents from IMD d1-5, 79\% reported a positive impact on their own perception of science, compared with $62 \%$ from IMD $\mathrm{d} 6-10$, a result that is statistically significant at $\mathrm{p}<0.05$ using a two-tailed chi-squared test.

Examples of comments from parents in the more deprived group included:
"[It has] changed how I feel about science."
"[It is] enlightening and very interesting."
"I like science more [now], more interested."

For some participants, seeing science in relation to their own children helped them to picture it in a different light. This point is illustrated by the experience reported at stage 4 by focus group participant Gemma. Gemma is a mother of a large family from a very deprived (IMD d1) area of Preston, is not a graduate and described herself as not very well informed about science. Asked if her visit had made her feel more positive about science, she commented:

\footnotetext{
"Yeah... When I've been at school, I really struggled with science. Because I struggled I wasn't really, like, keen on it. But bringing the children to the science festival, like they were hands on and that. Just seeing them. Yeah."
}

As discussed earlier, research has shown that parental attitudes to science are a predictor of a young person's future science participation. Having a parent who is interested in science is particularly important for those from traditionally underrepresented backgrounds; for this group, it is one of the strongest predictors of future science participation. Having a parent with an increased interest in science, or an enhanced vision of what science 'is', can support a young person's science aspirations.

Our research indicates that the experience of attending a science festival produced a stronger positive shift in perceptions of science among the group of parents whose children will most benefit from this. The experience of Gemma, whose perception of science was altered by seeing her children participate in it, illustrates 
this point. Gemma had a poor experience of science at school, which may have predisposed her to feel negative about the subject in relation to her children. However attending the festival helped her to see the subject in a different context, one in which her children could have a place.

\title{
ii. The breadth of science and science careers
}

Another key area of impact for which we sought evidence was in notions of the breadth of science. As explored above, an important barrier to science among low-science-capital families is a perception of science as 'narrow' and a lack of knowledge of what careers are available in the sector.

In our qualitative data gathered at stages $2 / 3$, comments about the broad range of science, often expressed in the context of surprise, were widespread. Comments included:

\footnotetext{
"There is so much more scope than I imagined and science is not just used in a lab."

"Really made you look at science in a different way. I never realised there were so many different science avenues!"
}

These comments were supported by the focus group discussion. When Nicola commented that she had been surprised by the breadth of science that people were involved with, the entire group quickly agreed. "There was a lot more variety than I expected," said Gemma. Participant Lily said:

\begin{abstract}
"It probably makes people think... People never realise that so many things are related to science. Like, for example, the toys children play with - you thought they were just toys, but you never think there's science behind it."
\end{abstract}

In particular, many stage $2 / 3$ participants reported having learned about jobs in science that they had not been previously aware of, and about the range of career opportunities more generally. Comments included: "Science features in a lot of careers I hadn't really thought about before - i.e. environmentalism," and "We have learnt that there are a huge variety of different occupations in [the] science field."

This theme was expressed by respondents from all backgrounds; for example, one parent from an IMD d1 area of Blackburn said:

\footnotetext{
"The sheer number of options that are science related is astounding. No longer is it just the stereotypical maths, engineering or science - it's hundreds of different domains that each lead onto fulfilling careers. A festival like this gives a very useful insight into the possibilities and paths that can be taken which might not have been explored before."
}

And a parent from an IMD d10 suburb of Preston said:

"I hadn't appreciated the endless possibilities a science background provides, from health to pyrotechnics!" 
This finding is potentially beneficial, because parents who are better informed about the range of science careers available are likely to see the benefit in continuing to study science and to be more likely to support children in such aspirations. Knowledge about science careers and the transferability of science qualifications is a component of science capital, and having parents who can discuss the utility of studying science is, as previously mentioned, a predictor of future science participation.

As one participating parent commented:

"Seeing the options available, the different fields, where it can take you career wise has made me encourage and be positive about science for my son."

In total, $52 \%$ of parents interviewed at stage 2 told researchers that they felt more positive about their children pursuing a career in science after visiting the LSF. However when we compare social groups we find evidence of differential impact. Of parents who lived in more deprived (IMD d1-5) areas, 59\% reported that they now felt more positive about science careers for their children, compared to $47 \%$ from IMD d6-10 areas. When we compare the most deprived group - individuals from IMD d1-3 areas - with everyone else, the effect is magnified, with $68 \%$ feeling more positive compared to $47 \%$ of others, a finding which is statistically significant at $\mathrm{p}<0.05$. As deprivation correlates with low science capital, increasing knowledge about the usefulness of science and the availability of science careers amongst this group has the potential to impact on their children's future science participation.

Another key theme emerging from the qualitative data was concepts of the accessibility and 'reality' of science. One parent said that the festival made science "more accessible, not scary", while another said that "the science professions seem open and accessible to all". This can have a bolstering effect for those with an existing interest in science; one parent said:

"My daughter already had a keen interest in science and this has just fuelled it. She can now see the reality in aiming to study science."

We know that young people in general enjoy science but that many, together with their families, see it as 'not for me'; notions of accessibility may help to combat this perception and instead support the idea that science is a career that many people can enter.

In a similar vein, many parents commented on the fact that attending had made them realise how prevalent science is in 'real life'; one said:

"There is so much about science and daily living that you do not realise. Going to these events truly opens your eyes."

These comments are significant, suggesting a diminution in the 'othering' of science. This, in turn, has the potential to lead to a lessening of the perception that science is a 'hard' thing that is done by scientists who are not 'people like us'. 


\section{iii. Encouraging informal science activity}

We posited that one benefit of festival attendance might be to boost informal out-of-school science activity, such as playing science-related games or talking about science, which is one predictor of future science participation.

In the stage 3 survey, a small number of parents reported that their children had engaged in science-related play or activities since their attendance at the festival.

"My 7-year-old came straight home and got all his science kits out of the cupboard and spent the rest of the weekend creating 'experiments'."

"The UCLan science festival has ignited a passion for my children playing 'scientists' — start them off young! Potions are the current favourite."

The families in this group were uniformly from highly affluent (IMD d9-10) areas, and the comments suggest that these are homes with existing science capital, as represented by science kits and/or knowledge about how to gather more science information. This picture was supported by findings from our focus group. Nicola, a respondent from an IMD d8 suburb of Preston, commented:

"They came home and did a lot of the things that they had seen which was lovely, so it wasn't just witnessing it on the day and talking about it."

However there is nuance in the question of who has science capital and who does not; the correlation with socioeconomic status is imperfect. Another focus group participant, Zainab, also mentioned that her children had come home from the festival and started playing with science kits that had been an unopened gift. Although Zainab lives in a highly deprived (IMD d1) area of Preston, she has a degree and described herself as fairly well informed about science.

Post-event family discussion of science was also spontaneously mentioned by high-SES respondents only. However comments by focus group participant Gemma suggest that there might be more to this picture. She said:

"My children, they kind of went round telling everybody, even people on the street, where they'd been and they talked about it for weeks... They didn't really do any of like the practical stuff like, but they did speak about it for weeks."

This demonstrates that while pre-existing family science capital may facilitate a boost in informal science activity following the festival, it is not a prerequisite. Talking about science in informal environments is an important facet of science capital, and here we see evidence that attending the festival has boosted this for Gemma's family. Had the children had the opportunity to participate in other activities, they may well have done so.

The results on this measure are less positive than on the first two theses, and our survey findings do not provide evidence for the suggestion that festival attendance 
could boost informal activity in families with lower science capital. However Gemma's experience suggests a potential way forward; festival organisers might consider whether it is possible to distribute take-home materials aimed at boosting such activities among families who do not have relevant resources at home, thereby widening potential post-festival participation beyond those families that are already invested in science. Whether festival attendance has the potential to systematically increase such interactions is a question that is worthy of further research.

\section{Conclusions}

The question of how we increase the proportion of young people pursuing post-compulsory science, particularly amongst underrepresented groups, is an intractable one, and some studies have shown that school-based informal science education interventions are of limited long-term effect. As the family environment is a key influence on science capital, we asked whether informal events aimed at families, such as science festivals, could impact on three areas with the potential to boost future science participation: parental attitudes to science, knowledge about the breadth and utility of science, and levels of participation in informal science activity.

We found that attendance at such an event can have a significant effect on parental views of science, with $70 \%$ of parents reporting a positive impact on their perception. This effect was particularly marked among parents from more deprived areas; those of lower SES were significantly more likely to report an improved perception of science. This is important because low SES is a proxy for low science capital, and young people from these groups are more strongly influenced by their parents' attitudes when choosing whether to participate in post-compulsory science.

We also found that one of the most common spontaneously-reported benefits of attendance was exposure to the breadth of science and available science careers. In addition, the festival helped to make science seem 'real' and 'accessible', perhaps going some way to combatting the stereotypical image of the 'brainy scientist' which can be a barrier to post-compulsory science participation. A majority of parents said that they felt more positive about their children pursuing science careers after visiting the festival, and this effect was particularly marked among families from the most deprived areas. As a lack of understanding of the utility of science and of the variety of science jobs is a feature of low-science-capital families, these impacts have the potential to boost future participation among these groups.

However our thesis that attendance could bolster informal science activities such as reading and conversations was not supported for those from more deprived groups; parents who reported this benefit were from affluent backgrounds who were able to provide both equipment, such as science kits, and knowledge to support such activities. This is an area that is worthy of further investigation; festival organisers could consider providing follow-up materials to boost post-festival informal science activity.

Despite this issue, we found that overall, attending an informal science event such as a festival can influence family perceptions of science and science careers, particularly among parents from more deprived areas. This suggests that such events could have a positive effect on promoting post- 16 science participation among their children. These findings come with an important caveat, however. Families who 
attend science festivals are, on average, more highly educated and more confident about science than the population as a whole. In order to maximise the public engagement benefits of such events, therefore, organisers must take a more active role in ensuring that their events reach the widest possible public. Further study into interviewer effects on individuals' self-perception of science knowledge would also be a valuable endeavour. Staging science festivals is a resource-intensive endeavour, and it is therefore imperative that further research is conducted into the question of what their impacts are and how their audience can be broadened.

\section{References}

Archer, L. and Dewitt, J. (2017). Understanding young people's science aspirations. Abingdon, U.K.: Routledge.

Archer, L. and Tomei, A. (2013). What influences participation in science and mathematics? A briefing paper from the Targeted Initiative on Science and Mathematics Education (TISME). London, U.K.: King's College London.

URL: https://kclpure.kcl.ac.uk/portal/files/64435093/TISME_briefing _paper_March_2013.pdf (visited on 23rd March 2018).

Archer, L., Dawson, E., DeWitt, J., Seakins, A. and Wong, B. (2015). "“Science capital": A conceptual, methodological, and empirical argument for extending Bourdieusian notions of capital beyond the arts'. Journal of Research in Science Teaching 52 (7), pp. 922-948. https://doi .org/10.1002/tea. 21227.

Archer, L., DeWitt, J. and Dillon, J. (2014). "It didn't really change my opinion”: exploring what works, what doesn't and why in a school science, technology, engineering and mathematics careers intervention'. Research in Science $\mathcal{E}$ Technological Education 32 (1), pp. 35-55. https://doi.org/10.1080/02635143.2013.865601.

Archer, L., DeWitt, J., Osborne, J., Dillon, J., Willis, B. and Wong, B. (2012). 'Science aspirations, capital and family habitus: how families shape children's engagement and identification with science'. American Educational Research Journal 49 (5), pp. 881-908. https: //doi .org/10 .3102/0002831211433290.

Banerjee, P. A. (2017). 'Is informal education the answer to increasing and widening participation in STEM education?' Review of Education 5 (2), pp. 202-224. https://doi.org/10.1002/rev3.3093.

Bevc, C., Young, D. and Peterman, K. (2016). ‘Using social network analysis to document science festival partnerships'. JCOM 15 (05), A04. https://doi.org/10.22323/2.15050204.

Bultitude, K. (2014). 'Science festivals: do they succeed in reaching beyond the "already engaged"?' JCOM 13 (04), C01. URL: http://jcom.sissa.it/archive/13/04/JCOM_1304_2014_C01.

Canovan, C. and Luck, C. (2018). 'Seeing for yourself: how "ambient information" shapes parental attitudes to higher education'. Widening Participation and Lifelong Learning 20 (4), pp. 148-168. https://doi.org/10.5456/NVPLL.20A.148.

Cleaves, A. (2005). 'The formation of science choices in secondary school'. International Journal of Science Education 27 (4), pp. 471-486. https://doi.org/10.1080/0950069042000323746.

Confederation of British Industry (2014). Engineering our future. URL: https://www.sciencecentres.org.uk/resources/stem-skills/enginee ring-our-future-stepping-urgency-stem/ (visited on 14th February 2018). 
Dabney, K. P., Chakraverty, D. and Tai, R. H. (2013). 'The association of family influence and initial interest in science'. Science Education 97 (3), pp. 395-409. https://doi.org/10.1002/sce.21060.

Dabney, K. P., Tai, R. H., Almarode, J. T., Miller-Friedmann, J. L., Sonnert, G., Sadler, P. M. and Hazari, Z. (2012). 'Out-of-school time science activities and their association with career interest in STEM'. International Journal of Science Education, Part B 2 (1), pp. 63-79. https://doi.org/10.1080/21548455.2011.629455.

Dawson, E. (2017). 'Social justice and out-of-school science learning: exploring equity in science television, science clubs and maker spaces'. Science Education 101 (4), pp. 539-547. https://doi.org/10.1002/sce.21288.

DeWitt, J., Archer, L. and Mau, A. (2016). 'Dimensions of science capital: exploring its potential for understanding students' science participation'. International Journal of Science Education 38 (16), pp. 2431-2449. https://doi.org/10.1080/09500693.2016.1248520.

Fogg-Rogers, L., Bay, J. L., Burgess, H. and Purdy, S. C. (2015). “'Knowledge is power": a mixed-methods study exploring adult audience preferences for engagement and learning formats over 3 years of a health science festival'. Science Communication 37 (4), pp. 419-451. https://doi.org/10.1177/1075547015585006.

Henderson, M., Sullivan, A., Anders, J. and Moulton, V. (2017). 'Social class, gender and ethnic differences in subjects taken at age 14'. The Curriculum Journal 29 (3), pp. 298-318. https://doi.org/10.1080/09585176.2017.1406810.

Hill, D. and Wheeler, A. (1991). 'Towards a clearer understanding of students' ideas about science and technology: an exploratory study'. Research in Science $\mathcal{E}$ Technological Education 9 (2), pp. 127-137. https://doi.org/10.1080/0263514910090202.

Jensen, E. and Buckley, N. (2014). 'Why people attend science festivals: interests, motivations and self-reported benefits of public engagement with research'. Public Understanding of Science 23 (5), pp. 557-573. https://doi.org/10.1177/0963662512458624.

Katz, D. (1942). 'Do interviewers bias poll results?' Public Opinion Quarterly 6 (2), pp. 248-268. https://doi.org/10.1086/265548.

Kennedy, E. B., Jensen, E. A. and Verbeke, M. (2017). 'Preaching to the scientifically converted: evaluating inclusivity in science festival audiences'. International Journal of Science Education, Part B 8 (1), pp. 14-21. https://doi.org/10.1080/21548455.2017.1371356.

Kirkpatrick, D. (1996). Evaluating training programs. San Francisco, U.S.A.: Berrett-Koehler.

Lin, P.-Y. and Schunn, C. D. (2016). 'The dimensions and impact of informal science learning experiences on middle schoolers' attitudes and abilities in science'. International Journal of Science Education 38 (17), pp. 2551-2572. https://doi.org/10.1080/09500693.2016.1251631.

Lloyd, R., Neilson, R., King, S. and Dyball, M. (2012). Review of Informal Science Learning. London, U.K. URL: https : //wellcome .ac .uk/what-we-do/our-work /increasing-informal-science-learning (visited on 14th September 2018).

Manning, C., Lin, K. and Goodman, I. F. (2013). The science festival alliance: creating a sustainable national network of science festivals - final summative evaluation report. URL: http://www.informalscience.org/sites/default/files/2013-08-09_S FA_2010-2012_Final_Evaluation_Report.pdf (visited on 6th April 2017). 
Matterson, C. and Holman, J. (2012). Informal science learning review: reflections from the Wellcome Trust. URL: https://wellcomelibrary . org/item/b21248047 (visited on 14th September 2018).

Nunes, T., Bryant, P., Strand, S., Hillier, J., Barros, R. and Miller-Friedmann, J. (2017). Review of SES and science learning in formal educational settings. URL: https://educationendowmentfoundation.org.uk/public/files/Review _of_SES_and_Science_Learning_in_Formal_Educational_Settings.pdf (visited on 11th April 2018).

Peterman, K. and Young, D. (2015). 'Mystery Shopping: An Innovative Method for Observing Interactions With Scientists During Public Science Events'. Visitor Studies 18 (1), pp. 83-102. https://doi .org/10.1080/10645578.2015.1016369.

Reiss, M. J. (2013). How can we get more students to study mathematics or physics? The UPMAP project.

URL: http://discovery.ucl.ac.uk/10018423/7/RB2_UPMAP_Reiss.pdf (visited on 26th January 2018).

Rose, K. M., Korzekwa, K., Brossard, D., Scheufele, D. A. and Heisler, L. (2017). 'Engaging the public at a science festival'. Science Communication 39 (2), pp. 250-277. https://doi .org/10.1177/1075547017697981.

Smith, E. and White, P. (2011). 'Who is studying science? The impact of widening participation policies on the social composition of U.K. undergraduate science programmes'. Journal of Education Policy 26 (5), pp. 677-699. https://doi.org/10.1080/02680939.2010.540676.

Tai, R. H., Liu, C. Q., Maltese, A. V. and Fan, X. (2006). 'Planning early for careers in science'. Science 312 (5777), pp. 1143-1144. https://doi.org/10.1126/science.1128690.

Author

Cherry Canovan is a research associate at the University of Central Lancashire. She obtained her PhD in Mathematical Physics from Lancaster University and previously worked as an education journalist. Her research interests include the impacts of science festivals, as well as widening participation in STEM and higher education more generally. E-mail: ccanovan@uclan.ac.uk.

\section{How to cite}

Canovan, C. (2019). "“Going to these events truly opens your eyes". Perceptions of science and science careers following a family visit to a science festival'. JCOM 18 (02), A01. https:/ / doi.org/10.22323/2.18020201. 